Richard Brull MD, John W. Bradley MD FRCPC

\title{
The role of anesthesiol- ogists in Canadian undergraduate medical education
}

Purpose: To examine the current role of anesthesio logists in $C$ anadian undergraduate medical education (UME). M ethods: A 93-item questionnaire was mailed to the undergraduate course chairs/coordinators for anesthesia at the 16 medical schools in Canada.

Results: Of the faculty anesthesiologists in Canada, 1.7\%, 4.9\%, and $4.9 \%$ teach pre-clerkship lectures, seminars, and PBL tuto rials, respectively. Annually, anesthesiologists teach an average of $3.3 \mathrm{hr}$ (range: 0 to 15) of preclerkship lectures and $12.8 \mathrm{hr}$ (range: 0 to 48) of pre-clerkship seminars at each medical school. The topics most commonly taught by anesthesiologists in pre-clerkship lectures and seminars are pharmacology and perioperative patient assessment, respectively. An anesthesia rotation during clerkship is mandatory at 13 schools, with an average duration of 9.6 dy (range: 5 - 20 dy). Clerkship teaching methods vary: ten schools provide seminars, eight use videos, six use computers, six use an airway skills laboratory, and four use an anesthesia simulator. The most common topics taught in clerkship anesthesia seminars are airway management and fluid therapy.

Conclusion: A very small proportion of faculty anesthesiologists participate in Canadian UME at the pre-clerkship level. Considerable variation exists in the amount and format of teaching by anesthesiologists among the Canadian undergraduate curricula, particularly at the pre-clerkship level. However, our results indicate that anesthesiologists are assuming a more important teaching role during clerkship. O ur findings may suggest that Canadian medical schools are overlooking the advantages that anesthesiologists offer to U ME at the pre-clerkship level, or that many anesthesiologists are reluctant to assume pre-clerkship teaching responsibilities.

Objectif : Examiner le rôle actuel des anesthésiologistes dans la formation canadienne des étudiants en médecine (FEM).

M éthode : Un questionnaire comportant 93 éléments a été posté aux directeurs/coordonnateurs des programmes d'anesthésie des seize écoles de médecine du Canada.

Résultats : Parmi les anesthésio logistes des corps d'enseignement du Canada, 1,7 \%, 4,9\% et 4,9\% offrent des cours d'avant-stage, des séminaires et le tutorat du programme d'apprentissage par problème (APP), respectivement. Annuellement, les anesthésiologistes enseignent en moyenne 3,3 h (intervalle : 0 à 15) sous forme de cours d'avant-stage et 12,8 h (intervalle : 0 à 48) de séminaires d'avant-stage à chaque école de médecine. Les sujets abordés le plus souvent pendant les cours et les séminaires sont respectivement la pharmacologie et l'évaluation périopérato ire du patient. Une rotation en anesthésie est obligatoire pour les stagiaires de treize écoles et dure en moyenne 9,6 jrs (intervalle : 5 - 20 jrs). Les méthodes d'enseignement varient : dix écoles offrent des séminaires, huit utilisent la vidéo, six font usage d'ordinateurs, six présentent un laboratoire de compétence en intubation et quatre utilisent un simulateur d'anesthésie. Pendant les séminaires sur l'anesthésie, le stagiaire entend surtout parler de la ligne de conduite à adopter pendant l'intubation et l'hydratation intraveineuse.

Conclusion : O n note un faible taux de participation des professeurs anesthésiologistes à la FEM canadienne pré-stagiaire. La quantité et la forme de l'enseignement prodigué par les anesthésiologistes auprès des étudiants en médecine du Canada varient beaucoup, particulièrement au niveau pré-stagiaire. Cependant, nos résultats indiquent que les anesthésiologistes enseignent davantage pendant les stages. N os observations peuvent laisser croire que les écoles de médecine canadiennes méconnaissent les avantages offerts par les anesthésiologistes à la FEM avant les stages ou que de nombreux anesthésiologistes sont réticents à assumer des responsabilités de professeur dans ce même cadre.

From the D epartment of Anesthesia, Faculty of M edicine, U niversity of T oronto, Toronto, O ntario, Canada.

A ddress correspondence to: D r. J ohn Bradley, D epartment of Anesthesia, Toronto G eneral H ospital, 585 U niversity Avenue, Bell Wing

4-645, T oronto, O ntario, M 5G 2C 4 Canada. Phone: 416-340-5164; Fax: 416-340-3698; E-mail: john.bradley@uhn.on.ca A ccepted for publication October 8, 2000. 
IVEN the broad-based knowledge and technical skill of anesthesiologists, they are a rich resource for undergraduate medical education (UME) ${ }^{1-5}$ Anesthesiologists are ideally suited to teach physiology, pharmacology, resus citation, pain management, perioperative assessment, and technological medicine. ${ }^{1,2}$ As intensivists, many anesthesiologists are well suited to teach medical ethics, including consent, allocation of scarce resources, and end-of-life decision-making. ${ }^{2,3}$ T oday's anesthesiologists also have unparalleled insight into the practice of ambulatory medicine and efficient health care management as increasingly more surgical patients are admitted to hos pital on the day of surgery, and most Canadian anesthesia departments manage busy pre-admission consultation clinics. ${ }^{6}$ Furthermore, anesthesiologists play an integral role in various hospital settings including the operating room, post-anesthesia care unit, ICU, pre-admission clinic, obstetrical ward, and pain clinic, all of which inherently translate into excellent teaching environments for problem-based learning (PBL). ${ }^{6}$ In fact, anesthesiologists have been teaching anesthesia res idents in a PBL format for decades, for example, daily in the operating room setting, weekly at the popular "Trouble Rounds" held at most Canadian teaching institutions, and monthly at "M orbidity and Mortality Rounds" ${ }^{6} \mathrm{~N}$ evertheless, the teaching potential of anes thesiologists in U M E has been greatly undervalued such that the role of anesthesiologists remains limited in many undergraduate curricula, mostly because tradition holds anesthesia a postgraduate subject, partly because of inadequate funding, and possibly because many clinicians are unaware of the tremendous breadth of contemporary anesthetic practice. ${ }^{2,3,7} \mathrm{H}$ owever, the recent shift by $\mathrm{N}$ orth American medical schools towards the small-group PBL model inevitably increases the demand for teaching faculty, and thus presents the ideal opportunity to engage anesthesiologists in various teaching roles within the reformed undergraduate curricula. The inaugural meeting of the $U$ ndergraduate $E$ ducation section of the Association of Canadian U niversity D epartments of Anesthesia (ACUDA) held in Calgary, Alberta, in June 1999 demonstrated considerable variability in the undergraduate anesthesia experience among the $\mathrm{C}$ anadian medical schools. ${ }^{6}$ An examination of the current role of anesthesiologists in Canadian UME is well due, hence the subject of our study.

\section{M ethods}

In January 2000, a 93-item questionnaire was sent to the undergraduate course chairs/ coordinators for anesthesia at each of the 16 medical schools in Canada. O ur questionnaire was generated from the proceedings of the 1999 ACUDA meeting and was divided into two main sections. Section 1 examined the participation of anesthesiologists in teaching at the pre-clerkship level, including lectures, seminars, and PBL tutorials. Also identified were the topics taught by anesthesiologists at the pre-clerkship level. Section 2 examined the clerkship anesthesia program, including the organization and duration of the mandatory clerkship anesthesia rotation, student evaluation processes, teaching methods, and clerkship electives. I nquiries regarding undergraduate administration and demographics were included at the end of the questionnaire.

The questionnaire was designed to be self-administered and predominantly in the form of yes/ no type questions, with some short-answer type questions. Written comments were solicited. Certain respondents were contacted via electronic mail in those few instances where reported answers required clarification.

Results

The chairs/ coordinators of undergraduate anesthesia education at all 16 medical schools in $\mathrm{C}$ anada responded to our questionnaire (100\% response rate). Table I demonstrates the number of faculty anesthesiologists at each medical school that participate in preclerkship lectures, pre-clerkship seminars, and pre-clerkship PBL tutorials. We found that $1.7 \%$, $4.9 \%$, and $4.9 \%$ of the total number of faculty anesthesiologists in Canada teach pre-clerkship lectures, seminars, and PBL tutorials, respectively. I nterestingly, the medical school with the least number of anesthesiologists on faculty (i.e. Q ueen's U niversity) reported the greatest proportions of faculty anesthesiologists involved in teaching both pre-clerkship lectures and pre-clerkship seminars. Annually, anesthesiologists teach an average of $3.3 \mathrm{hr}$ (range: 0 to 15) of preclerkship lectures and $12.8 \mathrm{hr}$ (range: 0 to 48 ) of preclerkship seminars at each medical school (Figure 1). The topics most commonly taught by anesthesiologists in pre-clerkship lectures are pharmacology (82\% of schools) and physiology (18\% of schools), while those most commonly taught by anesthesiologists in pre-clerkship seminars are perioperative patient assessment ( $44 \%$ of schools), airway management (33\% of schools), and pharmacology (33\% of schools). Eight schools provide "Link" courses designed to facilitate and integrate the transition between the pre-clerkship and clerkship levels; anesthesiologists teach in "Link" courses at five of these schools. Pre-clerkship anesthesia electives are offered at 11 schools, and anesthesiologists at all 16 schools are involved in career counseling sessions designed to familiarize medical students with the specialty of anesthesia as a career. 
A clerkship anesthesia rotation is mandatory at 13 medical schools. The duration and undergraduate year in which the rotation takes place are recorded in Table II. I mportantly, two medical schools intend to implement a mandatory clerkship anesthesia rotation in the near future. Table III lists the components used to evaluate student performance upon completion of the rotation. Anesthesiologists teach seminars as part of the rotation at 10 schools; the average number of seminars per rotation is 5.4. Figure 2 demonstrates that the topics most commonly taught in clerkship anesthesia seminars are airway management $(90 \%$ of schools) and fluid therapy ( $80 \%$ of schools). Clerkship teaching aids vary across the country: eight schools

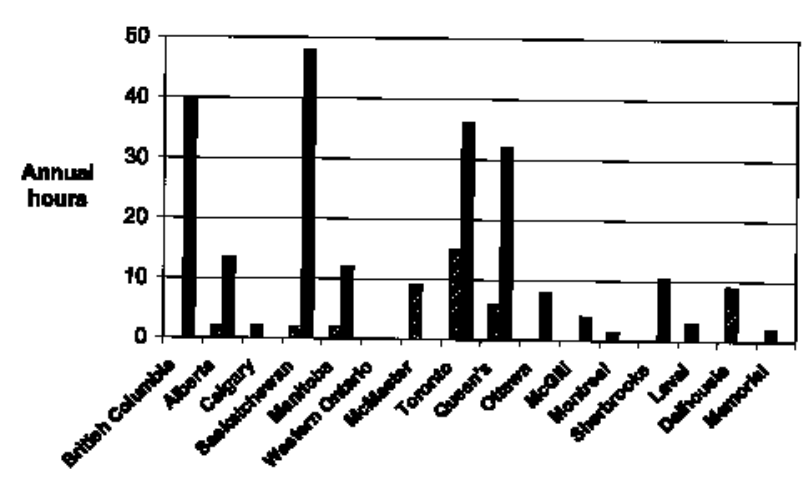

FIGURE 1 N umber of total annual hours of pre-clerkship lectures (shaded bars) and pre-clerkship seminars (black bars) taught by anesthesiologists at each medical school. use videos, six use computers, and six use an airway skills laboratory. An anesthesia simulator is currently available at five schools; four use their simulator for undergraduate teaching, and none use their simulator to evaluate student performance upon completion of the mandatory clerkship anesthesia rotation. Additionally, two medical schools plan to acquire a simulator for future use.

Anesthesia residents assume undergraduate teaching roles at 13 schools. Of these, all permit residents to teach medical students in the operating room setting and eight schools allow residents to teach undergraduate seminars. Only one of the five schools with an anesthesia simulator involves residents in teaching medical students using the simulator. Residents are formally evaluated on their undergraduate teaching skills at five medical schools.

All 16 medical schools offer clerkship anesthesia electives. Annually, each medical school accepts an average of 18.1 students to undertake a clerkship anesthesia elective for an average duration of $3.0 \mathrm{wk}$. U nfortunately, the anesthesia department at one medical school is continuously forced to decline the majority of medical students requesting clerkship electives due to an insufficient number of anesthesiologists.

There is a formal undergraduate education committee for anesthesia at 10 medical schools. Five schools have an anesthesiologist serving as the course director for at least one undergraduate course at the pre-clerkship level. Finally, the anesthesia departments at six schools are affiliated with a professional educator.

TABLE I N umber of faculty anesthesiologists participating in pre-clerkship lectures, pre-clerkship seminars, and pre-clerkship problembased learning (PBL) tutorials.

\begin{tabular}{|c|c|c|c|c|c|}
\hline Medical school & $\begin{array}{l}\text { N umber of faculty } \\
\text { anesthesiol ogists }\end{array}$ & $\begin{array}{l}\text { N umber of faculty } \\
\text { anesthes ologists } \\
\text { teaching lectures }\end{array}$ & $\begin{array}{l}\text { N umber of faculty } \\
\text { anesthes ol ogists } \\
\text { teaching seminars }\end{array}$ & $\begin{array}{l}\text { N umber of faculty } \\
\text { anesthesiologiss } \\
\text { teaching PBL tutorials }\end{array}$ & $\begin{array}{l}\text { N umber of faculty } \\
\text { anesthes ologists } \\
\text { writing PBL cases }\end{array}$ \\
\hline British Columbia & 140 & 0 & 10 & 6 & 2 \\
\hline Alberta & 80 & 1 & 3 & 0 & 0 \\
\hline Calgary & 100 & 2 & 0 & 1 & 1 \\
\hline Saskatchewan & 41 & 1 & 4 & 1 & 1 \\
\hline M anitoba & 60 & 2 & 3 & 0 & 2 \\
\hline Western O ntario & 53 & 0 & 0 & 2 & 0 \\
\hline M cM aster & 50 & 2 & 0 & 8 & 1 \\
\hline Toronto & 190 & 1 & 18 & 13 & 2 \\
\hline Queen's & 13 & 4 & 4 & 2 & 0 \\
\hline Ottawa & 62 & 0 & 4 & 4 & 0 \\
\hline M cGill & 66 & 0 & 3 & 0 & 0 \\
\hline M ontreal & 80 & 2 & 0 & 3 & 0 \\
\hline Sherbrooke & 22 & 0 & 4 & 4 & 1 \\
\hline Laval & 69 & 1 & 0 & 0 & 0 \\
\hline Dalhousie & 45 & 2 & 0 & 9 & 0 \\
\hline M emorial & 18 & 1 & 0 & 0 & 0 \\
\hline TOTAL & 1089 & 19 & 53 & 53 & 10 \\
\hline
\end{tabular}




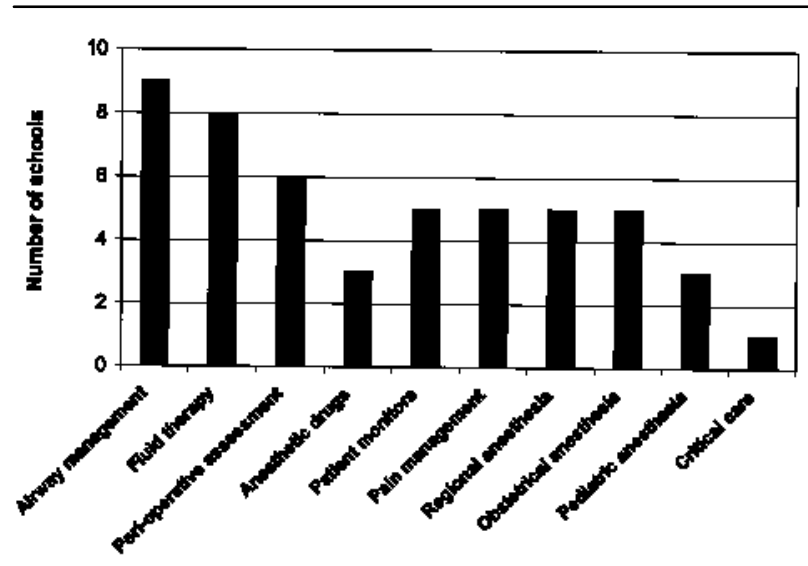

FIGU RE 2 Frequency of topics taught in clerkship anesthesia seminars.

TABLE II O rganization of the clerkship anesthesia rotation.

\begin{tabular}{|c|c|c|c|}
\hline M edical school & $\begin{array}{l}\text { Mandatory } \\
\text { anesthesia } \\
\text { rotation }\end{array}$ & $\begin{array}{l}\text { U ndergraduate } \\
\text { year at time of } \\
\text { rotation* }\end{array}$ & $\begin{array}{l}\text { Duration of } \\
\text { rotation } \\
\text { (days) }\end{array}$ \\
\hline British Columbia & Yes & $3 r d$ & 10 \\
\hline Alberta & Yes & 3rd or 4th & 5 \\
\hline Calgary & Yes & $3 r d$ & 10 \\
\hline Saskatchewan & Yes & 4 th & 10 \\
\hline M anitoba & Yes & $3 r d$ & 10 \\
\hline Western O ntario & Yes & $3 r d$ & 10 \\
\hline M cM aster & No & & \\
\hline Toronto & Yes & 4th & 10 \\
\hline Queen's & Yes & 4 th & 10 \\
\hline Ottawa & Yes & $3 r d$ & 10 \\
\hline McGill & Yes & 2nd & 5 \\
\hline M ontreal & Yes & 4th & 10 \\
\hline Sherbrooke & Yes & 4th & 5 \\
\hline Laval & Yes & 4th & 20 \\
\hline D alhousie & No & & \\
\hline M emorial & No & & \\
\hline
\end{tabular}

* M CM aster and C algary have three-year undergraduate medical programs; all other Canadian medical schools have four-year undergraduate medical programs.

\section{Discussion}

O ur results demonstrate that a very small proportion of faculty anesthesiologists in Canada participate in U ME at the pre-clerkship level. O ur findings may suggest that $C$ anadian medical schools are overlooking the advantages that anesthesiologists offer to U ME at the pre-clerkship level. Alternatively, the small number of anesthesiologists involved in pre-clerkship UME may reflect reluctance among anesthesiologists to undertake teaching responsibilities outside of the operating room, in large part due to inadequate funding. $\mathrm{N}$ evertheless, our results suggest that anesthesiologists complement the reformed pre-clerkship curricula as considerably more faculty anesthesiologists teach either PBL tutorials or seminars than lectures. Importantly, data accumulated by the U niversity of Toronto supports anesthesiologists as highly effective pre-clerkship teachers. ${ }^{8}$ Since 1996 , 6589 teacher evaluation forms have been collected from pre-clerkship students at the U niversity of T oronto, where multiple consultants from various specialties, including anesthesia, jointly teach in the preclerkship curriculum. With respect to teacher effectiveness, pre-clerkship students assigned anesthesiologists an average score of 8.73 out of 10 , while the average score for all other consultants was 8.56.

O ur findings also indicate that anesthesiologists are progressively assuming a more important teaching role in the clerkship setting compared with past years. Since a 1994 survey of the anesthesia departments at the 16 Canadian medical schools, ${ }^{9}$ the number of schools currently providing a minimum 10-day mandatory clerkship anesthesia rotation has increased by $43 \%$ It is noteworthy that although the optimal duration of undergraduate clinical anesthesia instruction has yet to be determined, the Royal College of Anaesthetists in the $U$ nited Kingdom advises a minimum of two weeks, ${ }^{4}$ while the authors of a recent study which surveyed undergraduate anesthesia teaching at 73 medical schools worldwide recommend four weeks. ${ }^{10}$

In the wake of Canada's current shortage of anesthesiologists, time and financial constraints restrict anesthesiologists' availability to participate in UME outside of the operating room setting. O ne potential remedy to enhance the contribution that anesthesiologists make to U ME may be to hold teaching sessions outside traditional daytime schools hours. For example, we found that $50 \%$ of all PBL tutorials at M CM aster U niversity take place after 5:00 p.m. in order to accommodate the unyielding daytime schedules of PBL tutorial leaders. M oreover, anesthesia simulators may prove efficient since simulator sessions could be videotaped for future viewing such that anesthesiologists need not defer their daytime clinical duties in order to evaluate medical students. $\mathrm{H}$ owever, despite encouraging data supporting the validity and objectivity of the simulator in evaluating medical student performance, ${ }^{11}$ we found that none of the five Canadian schools with a simulator incorporate their simulator into the student evaluation process of the mandatory clerkship anesthesia rotation. Finally, in order to attract additional anesthesiologists to UME, an active commitment to teaching should be consid- 
TABLE III M ethods of student evaluation upon completion of mandatory clerkship anesthesia rotation (expressed as relative percent value of final evaluation).

\begin{tabular}{|c|c|c|c|c|c|}
\hline Medical school & Clinical kills evaluation & Written evaluation & Oral evaluation & OSCE* & Other \\
\hline British Columbia & 30 & 70 & & & \\
\hline Alberta & 50 & 50 & & & \\
\hline Calgary & 33 & 33 & 33 & & \\
\hline Saskatchewan & 50 & 50 & & & \\
\hline$M$ anitoba & 75 & & 25 & & \\
\hline Western Ontario & 90 & & 10 & & \\
\hline M cM aster & $\mathrm{N}$ ot applicable & & & & \\
\hline Toronto & 40 & 60 & & & \\
\hline Queen's & 33 & 33 & 33 & & \\
\hline Ottawa & 40 & 20 & & 20 & 20 \\
\hline M cGill & 75 & 25 & & & \\
\hline M ontreal & 70 & 30 & & & \\
\hline Sherbrooke & & 100 & & & \\
\hline Laval & 80 & & 20 & & \\
\hline Dalhousie & $\mathrm{N}$ ot applicable & & & & \\
\hline M emorial & $\mathrm{N}$ ot applicable & & & & \\
\hline
\end{tabular}

$*$ OCSE $=0$ bjective Structured Clinical Examination.

ered equivalent to research endeavours for academic appointment and funding within each institution.

The time is ripe to enlist other anesthesia teaching resources, placing particular importance on anesthesia residents. O ur review of the literature revealed no data regarding the teaching potential of anesthesia residents at the undergraduate level, but found the value of residents as teachers in other specialties, including internal medicine, surgery and pediatrics, to be highly favourable.12-16 Furthermore, the residency training objectives of the Royal College of Physicians and Surgeons of $\mathrm{C}$ anada emphasize teaching as a necessary skill to become a competent anesthesia consultant. Although we found that anesthesia residents are assuming teaching roles at over $80 \%$ of the residency training programs in $\mathrm{C}$ anada, additional investigation is required to assess the quality and outcome of undergraduate teaching by anesthesia residents.

As the demand for anesthesiologists in C anada continues to outstrip the supply, the importance of recruiting future anesthesia residents cannot be overstated. Interestingly, Yang and associates demonstrated that no correlation exists between the quantity of anesthesia-related theory and practicum exposure in Canadian medical schools and the number of students entering anesthesia residency training programs in Canada. ${ }^{9}$ In fact, the greatest influence on specialty choice stems first from the interplay of faculty members and clinical experiences, and second from faculty members by themselves; clinical experiences alone affect few students' career choice. ${ }^{17} \mathrm{M}$ oreover, members of the teaching faculty exercise a strong role- modeling effect upon students throughout medical school. ${ }^{17} \mathrm{~A}$ recent Australian study indeed found that $94 \%$ of students intending a career in anesthesia identified positive role models in the anesthesiologists they had met during medical school. ${ }^{18} \mathrm{~T}$ he involvement of anesthesiologists in all aspects of UME is therefore essential in order to recruit much-needed future residents to our specialty. 2,19

In view of the considerable heterogeneity of educational activities described as "PBL" at different medical schools, ${ }^{20}$ we did not quantify the number of hours that anesthesiologists teach pre-clerkship PBL tutorials. We believe that this limitation does not undermine our study's main findings. In addition, we recognize the usefulness of data quantifying the involvement of other consultants, including internists, surgeons, and pediatricians, in pre-clerkship U ME as a means of comparison with our study's findings. $\mathrm{H}$ owever our review of the literature revealed no such reports. Finally, it is our assumption that the majority of faculty anesthesiologists take part in one-on-one teaching inside the operating room with students during the mandatory clerkship anesthesia rotation; therefore, we did not attempt to quantify anesthesiologist participation in teaching at the clerkship level.

In conclusion, we found that a very small proportion of faculty anesthesiologists in Canada participate in UME at the pre-clerkship level. Considerable variation exists in the amount and format of teaching by anesthesiologists among the Canadian undergraduate medical curricula, particularly at the pre-clerkship level. $\mathrm{H}$ owever, our results indicate that the teaching role of 
anesthesiologists during clerkship is progressively more prominent. O ur findings may suggest that Canadian medical schools are overlooking the advantages that anesthesiologists offer to U M E at the pre-clerkship level, or that many anesthesiologists are reluctant to assume pre-clerkship teaching responsibilities. To investigate the reasons why more anesthesiologists do not participate in pre-clerkship UME - with a view towards improvement - would be a worthwhile future endeavour.

\section{Acknowledgments}

We are most grateful to $\mathrm{Dr}$. D oreen Cleave-H ogg for her helpful comments in preparing our survey and reviewing earlier versions of our manuscript, and to M s. Karen Landells for her diligent work in collecting our data.

\section{References}

1 Prys $R$ oberts C, Cooper GM, H utton P. Anaesthesia in the undergraduate medical curriculum (Editorial). $\mathrm{Br}$ J Anaesth 1988; 60: 355-7.

2 Cooper GM, H utton P. Anaesthesia and the undergraduate medical curriculum (Editorial). $\mathrm{Br}$ J Anaesth 1995; 74: 3-5.

3 Royal College of Anaesthetists. Academic departments of anaesthesia in undergraduate education: an undervalued resource. London: Royal College of Anaesthetists; 1990.

4 Cooper GM, H utton P. Anaesthesia in the undergraduate curriculum. I n: Zorab J, Vickers M D, H armer M (Eds.). Principles of Education and Training. London: Baillière Tindall, 1994: 563-74.

5 Cooper GM, Prys R oberts $C$. Anaesthesia and resuscitation in the undergraduate curriculum. In: Dinnick OP, Thompson PW (Eds.). Some Aspects of Anaesthetic Safety. London: Baillière Tindall, 1988: 243-52.

6 Bradley JW. Can anesthesiologists be effective teachers in the reformed curriculum? In: $12^{\text {th }}$ World Congress of A naesthesiologists abstracts and proceedings [CDROM ]. Proceedings of the 12 th World Congress of Anaesthesiologists; 2000 J une 4-9; M ontreal, Canada: 40-2.

7 Eagle CJ. Anaesthesia and education. Can J Anaesth 1992; 39: 158-65.

8 Pike A. U ndergraduate teacher evaluation scores: 1996-2000. Toronto: U niversity of Toronto, Faculty of Medicine; 2000.

9 Yang $\mathrm{H}$, Wilson- $\mathrm{Y}$ ang $\mathrm{K}, \mathrm{R}$ aymer $\mathrm{K}$. Recruitment in anaesthesia: results of two national surveys. $C$ an J Anaesth 1994; 41: 621-7.

10 Cheung V, Critchley LA H , H azlett C, W ong ELY, Oh $T E$. A survey of undergraduate teaching in anaesthesia. Anaesthesia 1999; 54: 4-12.
11 M organ PJ, CleaveH ogg D. Evaluation of medical students' performances using the anesthesia simulator. Acad M ed 1999; 74: 202.

12 Byrne N, Cohen R. O bservational study of clinical clerkship activities. J M ed Educ 1973; 48: 919-27.

13 Y edidia MJ, Schwartz M D, H irschkorn C, Lipkin M Jr. Learners as teachers: the conflicting roles of medical residents. J Gen Intern M ed 1995; 10: 615-23.

14 Wipf JE, Pinsky LE, BurkeW. Turning interns into senior residents: preparing residents for their teaching and leadership roles. A cad M ed 1995; 70: 591-6.

15 Pelletier M, Belliveau P. R ole of surgical residents in undergraduate surgical education. C an J Surg 1999; 42: 451-6.

16 Johnson CE, Bachur R, Priebe C, BarnesR uth A, Lovejoy FH J r, $\mathrm{H}$ afler JP. Developing residents as teachers: process and content. Pediatrics 1996; 97 : 907-16.

17 Paiva REA, Vu N V, Verhulst SJ. The effect of clinical experiences in medical school on specialty choice decisions. J M ed Educ 1982; 57: 666-74.

18 Watts R W, MarleyJ, W orley P. U ndergraduate education in anaesthesia: the influence of role models on skills learnt and career choice. Anaesth Intensive Care 1998; 26: 201-3.

19 A lexander LA, M iller JN. Anesthesiology in medical school: reaching, teaching, and recruiting students. Acad M ed 1989; 64: 485.

20 M audsley G. Do we all mean the same thing by "problem-based learning"? A review of the concepts and a formulation of the ground rules. Acad M ed 1999; 74: 178-85. 